Saraswati, P. (2019). Kemampuan self regulated learning ditinjau dari achievement goal dan kepribadian pada pelajar usia remaja. Indigenous: Jurnal Ilmiah Psikologi, (4)2, 69-78. https://doi. org/10.23917/indigenous.v4i2.7209

\title{
Kemampuan Self Regulated Learning Ditinjau dari Achievement Goal dan Kepribadian pada Pelajar Usia Remaja
}

\author{
Putri Saraswati \\ Universitas Muhammadiyah Malang \\ psaraswati@umm.ac.id
}

\begin{abstract}
Abstrak. Remaja yang berada dalam lingkungan akademik dan pendidikan memiliki tuntutan dalam menyelesaikan tugas-tugas akademik sehingga membutubkan keterampilan dan kemampuan dalam meregulasi diri sebab akan memengaruhi proses belajarnya, seperti performanya dalam menyelesaikan tugas akademik. Faktor Self Regulated Learning (SRL) dari dalam diri berupa kepribadian dan tujuan khusus (achievement goal) berpengaruh terhadap kemampuannya dalam melakukan regulasi diri dalam belajar. Penelitian ini bertujuan untuk mengetahui pengaruh self regulated learning ditinjau dari kepribadian (OCEAN) dan achievement goal (Mastery dan Performance Orientation) pada pelajar usia remaja. Metode penelitian yang digunakan adalah kuantitatif, dengan cluster random sampling, dengan subjek sebesar 388 siswa SMA baik laki-laki maupun perempuan yang duduk di kelas 1, 2, dan 3. Data yang diperoleh akan diuji dengan menggunakan teknik statistik struktural equation modelling (SEM). Penelitian ini memperoleh hasil bahwa achievement goal berpengaruh terhadap SRL. Hanya kepribadian openess dan conscientiousness yang berpengaruh terhadap SRL.
\end{abstract}

Kata kunci: achievement goals; personality; self regulated learning; youth.

Abstract. Adolescents who are in an academic and educational environment have demands in completing academic tasks so that they need skills and abilities in self-regulation because it will affect their learning process, such as their performance in completing academic assignments. The Self Regulated Learning (SRL) factor of the self in the form of personality and special goals (achievement goal) influences its ability to conduct self-regulation in learning. This study aims to determine the effect of self-regulated learning in terms of personality (OCEAN) and achievement goals (Mastery and Performance Orientation) in adolescent students. The research method used is quantitative, with cluster random sampling, with a subject of 388 high school students both male and female who are sitting in grades 1, 2, and 3. The data obtained will be tested using statistical structural equation modelling (SEM) techniques. This study found that achievement goals had an effect on SRL. Only openess personality and conscientiousness affect SRL.

Keywords: achievement goals; personality; self regulated learning; youth.

\section{PENDAHULUAN}

Remaja diartikan sebagai masa perkembangan transisi antara masa anak ke masa dewasa yang mengalami perubahan pada kondisi biologis, kognitif, dan sosio-emosionalnya (Santrock, 2003). Perubahan yang terjadi berdampak pada perilaku remaja. Perubahan yang dialami remaja pada masa transisi menuju sekolah menengah lanjutan menimbulkan stres sebab terjadi secara bersamaan dengan transisi lainnya dalam diri individu, keluarga, dan sekolah (Ecccles, dkk., 1993; Estrada, 1992; Fenzel \& Blyth, \& Simmons, 1991; Hawkins \& Bernt, 1985; Simmons \& Blyth, dalam Santrock, 2003). Perubahan yang 
terjadi meliputi meningkatnya tanggung jawab dan kemandirian sebab menurunnya tingkat ketergantungan dengan orang tua; perubahan struktur kelas dari kelas kecil ke kelas besar di sekolah; dan perubahan pada peningkatan perhatian pada prestasi.

Perubahan lain yang terjadi adalah perubahan emosi dan sosial, di mana remaja akan lebih banyak menghabiskan waktunya untuk berinteraksi dengan teman dan lawan jenis dibandingkan keluarga atau orang tua. Perubahan ini berdampak pula pada perfoma akademik remaja untuk menyelesaikan tugas-tugas sekolah. Ada remaja yang lebih memilih kelompok sebayanya atau lawan jenis dibandingkan tugas-tugas akademiknya. Sebagaian dari remaja membuat kelompok sebayanya sebagai penyemangat dalam menyelesaikan tugas sekolah.

Perubahan ini terjadi karena, remaja banyak menghabiskan waktunya di sekolah. Di Indonesia sendiri, dengan adanya kebijakan full day school, membuat remaja semakin lama berada di sekolah dan dituntut untuk menyelesaikan banyak tugas sekolah. Menurut Peraturan Menteri Pendidikan Dan Kebudayaan Republik Indonesia, (n.d.) anak dan remaja berada di sekolah selama 8 jam per hari selama 5 hari. Meskipun hal ini tidak wajib, namun sekolah yang menerapkan sistem ini membuat remaja memiliki tugas akademik yang lebih banyak dibandingkan pada beberapa tahun yang lalu.

Tugas-tugas akademik yang banyak ini menuntut lebih banyak perhatian dan tenaga mereka untuk menyelasaikannya. Tidak jarang, remaja mengalami kelelahan dan berdampak pada kondisi psikologis remaja. Hal ini sejalan dengan penelitian yang pernah dilakukan sebelumnya bahwa pelajar yang menjalani proses belajar dengan full day school dari pukul 8 pagi hingga 5 sore mengalami kesulitan dalam menyesuaikan diri dengan jam tambahan di sekolah, merasakan bosan dan lelah berada di sekolah (Rizky, 2015; Winarni, 2015).

Fenomena yang terjadi di Kota Malang sendiri, berdasarkan hasil wawancara peneliti, diketahui bahwa, remaja SMA yang bersekolah dengan tugas akademik yang banyak, selama
8 jam di sekolah merasakan lelah yang amat sangat. Hal ini berdampak pada kurang adanya waktu untuk berkomunikasi dan meluangkan waktu untuk bercengkrama dengan keluarga khususnya orang tua. Selain itu, waktu di akhir pekan digunakan untuk tidur, sedangkan waktu usai sekolah digunakan untuk mengerjakan tugas-tugas dari sekolah. Secara sosial-emosi, hal ini membuat remaja menjadi kurang dekat dengan keluarga, dan cenderung acuh dengan lingkungan di rumah. Oleh karena itu, penting adanya kemampuan untuk meregulasi diri dalam belajar.

Dampak negatif lain dari kurang mampunya remaja dalam mengelola dirinya dalam belajar, tidak hanya terjadi pada remaja yang bersekolah dengan sistem fullday, namun juga pada remaja yang bersekolah dengan sistem yang biasa. Seperti yang dilansir pada harian surya malang, "Data kami tahun lalu, 65 persen adalah siswa luar Kota Malang yang membolos dan main ke Kota Malang," kata Kepala Dinas Pendidikan Kota Malang, Zubaidah. Berdasarkan hasil operasi dua hari berturut-turut, Rabu (11/1/2017) dan Kamis (12/1/2017), ada 36 siswa SMP dan SMA sederajat yang terjaring. Sebagian besar dari jumlah siswa itu adalah siswa yang bersekolah di Kota Malang.

Diperlukan adanya kemampuan remaja dalam mengelola kegiatan belajarnya. Dari sudut pandang psikologi, kemampuan mengelola kegiatan belajar disebut juga dengan self regulated learning. Self regulated learning atau biasa disingkat dengan SRL ini adalah kemampuan seseorang dalam merencanakan, memonitor, mengontrol, dan mengevaluasi dirinya dalam kegiatan belajar. Hal ini sejalan dengan pendapat (Pintrich, 2000) bahwa SRL merupakan suatu proses yang aktif di mana seseorang membuat target untuk kegiatan belajarnya dan berusaha untuk memonitor, mengelola dan mengontrol kognitif, motivasi dan perilakunya, sehingga dapat mengarahkan pada tujuan mereka dan karakter kontekstual di lingkungannya. Aktivitas regulasi diri ini dapat memediasi hubungan antara individu dan konteks lingkungannya, serta seluruh prestasi yang ditujunya. 
SRL menuntut remaja untuk dapat melakukan perencanaan, pemonitoran, evaluasi dan pengendalian terhadap aspek kognitif, motivasi dan perilakunya dalam belajar. Remaja yang mampu menerapkan SRL maka akan memiliki performa akademik yang baik, sehingga dapat menghasilkan prestasi akademik yang baik pula. Hal ini sejalan dengan hasil penelitian Broadbent \& Poon (2015) SRL memiliki hubungan dengan prestasi akademik. Sementara itu, remaja dengan SRL yang buruk akan mengalami ketidakkonsistenan dalam performa akademiknya. Hal yang terburuk adalah rendahnya kualitas performa akademik dan rendahnya prestasi akademik di sekolah. Zimmerman, B.J., Bonner, S., dan Kovach (1996) menyatakan bahwa perbedaaan pelajar berprestasi akademik tinggi dengan prestasi akademik yang rendah, terletak pada kemampuan dalam menentukan tujuan belajar, strategi belajar, dan memonitor diri dalam belajar dan beradaptasi secara sistematis dengan hasil belajar yang diperoleh.

Kemampuan self regulated yang dimiliki remaja salah satunya dipengaruhi oleh diri individu sendiri. Salah satu faktor dari dalam diri yaitu kepribadian, seperti yang dapat disarikan dari pendapat Matthew, Schwean, Campbell, Saklofske, dan Mohamed (dalam Boekaerts, Pintrich, \& Zeidner, 2000) bahwa kepribadian dapat memengaruhi proses regulasi diri. Kepribadian merupakan suatu organisasi yang dinamis, di dalam diri seseorang yang merupakan sistem psikofisik yang membentuk karakteristik seseorang yang terwujud dalam perilaku, pikiran, dan perasaan Allport (dalam (Hewstone, M. R. ,Fincham, F. D., \& Foster, 2005). Remaja yang memiliki kepribadian neurotic, jika mendapatkan informasi dari lingkungan tentang adanya ujian dadakan, maka akan membuatnya menjadi cemas dan akan mengalami kesulitan untuk melakukan regulasi diri dalam belajarnya.

Menurut Schultz, dan Schultz (2006), kepribadian neurotic memiliki karakteristik cemas, tidak aman, dan gugup; kepribadian extraversi digambarkan sebagai individu yang senang berinteraksi sosial, banyak bicara, menyenangkan, dan afektif. Kepribadian openess memiliki ciri asli/original, bebas, kreatif, dan berani. Kepribadian agreeableness dengan karakter mengayomi, menyayangi, dapat dipercaya, berhati lembut, dan sopan. Kepribadian conscientiousness dengan ciri perhatian, dapat dipercaya, pekerja keras, dan tertata/organized. Berdasarkan gambaran kepribadian ini, dapat diketahui bahwa individu dengan kepribadian tertentu maka akan memengaruhi kemampuannya dalam meregulasi diri dalam belajar.

Tipe kepribadian conscientiousness dan openess dapat memprediksi performa siswa di sekolah pada remaja (John dkk, 1994; Robins dkk, 1994 dalam (John, Robins, \& Pervin, 2008). Tipe kepribadian conscientiousness dapat memprediksi nilai akademik yang tinggi (Noftle \& Robins, 2007; Paunonem, 2003 dalam (John et al., 2008), sedangkan kepribadian openness dapat memprediksi lamanya studi pada dewasa tengah (Goldberg, Sweeney, Merenda \& Hughes, 1998 dalam (John et al., 2008).

Faktor dari dalam diri yang memengaruhi regulasi dalam belajar adalah tujuan. Tujuan berprestasi (achievement goal) merupakan salah satu dari konstrak motivasi di mana goalorientasi/ achievement goal ini memiliki hubungan dengan proses SRL (Pintrich, 2000). Remaja akan lebih mudah melakukan regulasi diri dalam belajar, saat dirinya memiliki tujuan yang jelas dalam belajar. Menurut Schunk dan Pintrich (2008) siswa yang memiliki tujuan dalam mencapai keinginannya akan terlibat dalam kegiatan yang dapat menunjang pencapaian keinginannya tersebut dengan cara memperhatikan proses, berlatih mengingat informasi, berusaha, dan bertahan.

SRL diarahkan oleh tujuan individu Pintrich (dalam Boekaerts et al., 2000) menyatakan, tujuan merupakan komponen penting dalam membentuk SRL. Tujuan dalam SRL digunakan untuk mengukur apakah proses dalam SRL dapat dilanjutkan atau diubah tipenya, jika diperlukan. Salah satu fase dalam SRL adalah perencanaan dan goal setting, di mana pembelajar membuat rencana dan tujuan yang akan dicapai dalam hal pembelajaran. Pembelajar mempersepsi dan merencanakan 
akan tugas-tugas yang akan dilakukan guna mencapai tujuan (goal) dalam hal akademik. Selain itu, pada fase ini juga merencanakan konteks yang berhubungan dengan tugas.

Tujuan (goal) dalam SRL terbagi menjadi dua, yaitu target (task-specific goals) yang berarti tujuan khusus yang akan dicapai dan purpose goal (goal orientation) yakni alasan umum pembelajar mengerjakan tugas dan berhubungan dengan motivasi berprestasi (Pintrich, dalam (Boekaerts et al., 2000). Adanya tujuan (goal orientation) maka pembelajar mengetahui alasan, mengapa pembelajar melakukan proses pembelajaran dan membuat target terhadap pembelajaran yang dilakukan serta bagaimana melakukan SRL.

Berdasarkan penjabaran di atas, maka peneliti bermaksud untuk melakukan penelitian dengan tujuan, antara lain untuk mengetahui pengaruh SRL ditinjau dari achievement goal dan kepribadian (OCEAN). Sementara rumusan masalah yang akan diungkap, apakah terdapat pengaruh SRL ditinjau dari achievement goal dan kepribadian (OCEAN). Hasil penelitian ini bermanfaat untuk memperkaya temuan ilmiah dalam ilmu Psikologi Pendidikan, serta memberikan masukan bagi siswa terkait goal achievement yang harus mereka buat dan SRL yang harus mereka kuasai.

\section{METODE PENELITIAN}

Jenis penelitian yang digunakan dalam penelitian ini adalah penelitian kuantitatif. Variabel pada penelitian ini yaitu variabel bebas (X1) kepribadian, variabel bebas (X2) adalah achievement goal / goal orientation dan variabel terikat (Y2) yakni SRL. Semantara itu, populasi pada penelitian ini adalah (a) Remaja akhir, usia 15 hingga 18/20 tahun (Santrock, 2003); (b) Pela- jar SMA aktif/sederajat di Kota Malang.

Sampel pada penelitian ini diambil dengan cara cluster random sampling. Metode cluster random sampling digunakan karena poulasi pada penelitian ini sangat luas yakni pelajar SMA aktif di Kota Malang. Pengambilan sampel dilakukan dengan mengambil sekolah secara acak di setiap kecamatan yang ada di Kota Malang, tanpa memperhatikan latar belakang sekolah tersebut negeri ataupun swasta. Sampel pada penelitian ini sebanyak 388 siswa baik laki-laki maupun perempuan, kelas 1, 2, dan 3.

Penelitian ini menggunakan skala dalam bentuk likert untuk mengempulkan data pada variabel SRL. Skala SRL akan dibuat oleh peneliti menggunakan dimensi-dimensi yang ada dalam teori ini. Dimensi ini meliputi fase perencanaan, fase performance, dan fase refleksi diri. Validitas dari skala ini antara 0,310 sampai 0,741 dengan reliabilitas sebesar 0,943 .

Data dari variabel orientasi tujuan/tujuan berprestasi diperoleh dengan menggunakan skala likert yang akan dibuat peneliti dari teori goal orientasilachievement goal. Dimensi dari alat ukur ini meliputi orientasi penguasaan/mastery dan orientasi performa. Koefisien reliabilitasnya sebesar 0,824 dan nilai validitas bergerak dari 0,280 hingga 0,613.

Pengumpulan data variabel kepribadian digunakan tes kepribadian dari Eyesenk "Big five". Alat tes kepribadian ini terdiri dari lima jenis kepribadian yakni extraversion, agreableness, openness, conscientiousness, neuroticism dengan validitas, dan reliabilitas (Tabel 1).

Indeks validitas alat ukur bergerak dari 0,301 sampai dengan 0,665 . Sedangkan indeks reliabilitasnya diukur dengan alpha cronbach dan tiap aspek memiliki nilai lebih dari 0,7. Nilai reliabilitas yang paling tinggi 0,811 pada

Tabel 1. Validitas dan Reliabilitas alat ukur

\begin{tabular}{lcc}
\hline \multicolumn{1}{c}{ Jenis Kepribadian } & Indeks Validitas & Alpha \\
Openness & $0,374-0,665$ & 0,798 \\
Concientiouness & $0,353-0,620$ & 0,811 \\
Extraversion & $0,393-0,635$ & 0,796 \\
Agreeableness & $0,301-0,571$ & 0,737 \\
Neuroticism & $0,309-0,614$ & 0,716 \\
\hline
\end{tabular}

72 | Kemampuan Self-Regulated... 
aspek concientiouness.

Data yang telah diperoleh dalam penelitian ini, dilakukan analisa dengan menggunakan teknik analisa SEM dengan melihat pengaruh antara variabel kepribadian dan achievement goal terhadap self-regulated learning. Dalam pelaksanaannya, peneliti akan menggunakan software lisrel.

\section{HASIL DAN PEMBAHASAN}

Nilai t variabel extraversi, agreeble, dan neurotik (Gambar 1) lebih kecil dari pada t tabel $(1,20<1,98 ; 1,60<1,98 ;-0,069<1,98)$ maka dapat diartikan bahwa pengaruh variabel extraversi, agreeble, dan neurotik tidak signifikan pada taraf signifikansi $5 \%$. Selanjutnya untuk variabael consciens dan openess memiliki koefisiensi nilai t lebih besar dari t tabel $(7.03>1,98$ dan $8,50>1,98)$, artinya pengaruh consciens dan openess signifikan terhadap kepribadian pada taraf signifikansi 5\%. Selanjutnya pengaruh kepribadian terhadap SRL bila dilihat dari nilai t juga tidak signifikan pada taraf signifikansi 5\% ( $\mathrm{t}$ hitung $=0,10<\mathrm{t}$ tabel $=1,98$ ).

Pada variabel achievement goal terlihat koefisien nilai t signifikan pada taraf signifikansi 5\% bila membandingkan thitung dengan $t$ tabel. Untuk variabel mastery approach, mastery avoidance, performance approach, dan perfor- mance avoidance signifikan berpengaruh terhadap achievement goal $(15,59>1,98 ; 10,86>$ 1,98; 9,60 > 1,98; dan 7,70 > 1,98). Sehingga tidak mengherankan jika varibale achievement goal memiliki pengaruh yang signifikan terhadap SRL pada taraf signifikansi 5\% (3,48 > 1,98).

Pada variabel endogen yakni SRL dapat dilihat bahwa variabel Y yakni kognitif tidak menunjukkan koefisien t. Variabel performance dan self reflection menunjukkan koefisien nilai $\mathrm{t}$ yang signifikan dalam memengaruhi SRL $(18,08$ $>1,98$ dan $17,96>1,98)$.

Berdasarkan pada bagan 2, dapat diketahui bahwa $\mathrm{df}>0(\mathrm{df}=51)$ maka model SEM dapat dilakukan. Selain itu, pada gambar juga terlihat nilai chi-square besar yakni 107,31 dan nilai p mendekati 0,0000 yakni 0,00001 serta memiliki RMSEA lebih kecil atau sama dengan dari 0,05 (RMSEA=0,053). Artinya model di atas fit.

Pada bagan 2 dapat dilihat koefisien extraversi terhadap kepribadian sebesar 0,15 , koefisien agreebel terhadap kepribadian sebesar 0,24, pengaruh conscient terhadap kepribadian sebesar 0,97 , pengaruh neurotis terhadap kepribadian sebesar -0,09 dan pengaruh openess terhadap kepribadian sebesar 1,80. Artinya secara umum seluruhnya memiliki pengaruh positif terhadap kepribadian kecuali neurotik terhadap kepribadian. Meskipun demikian, yang

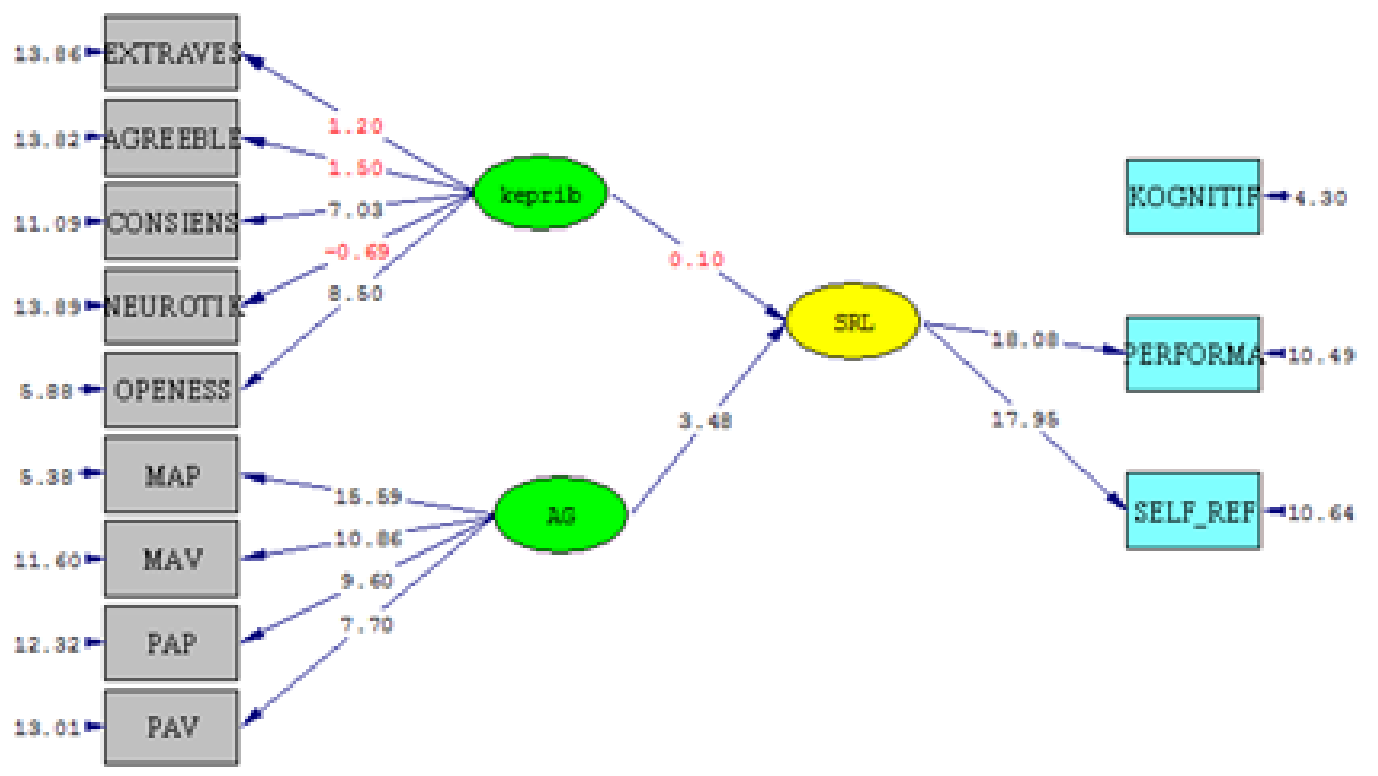

Gambar 1. Hasil analisis SEM 1 


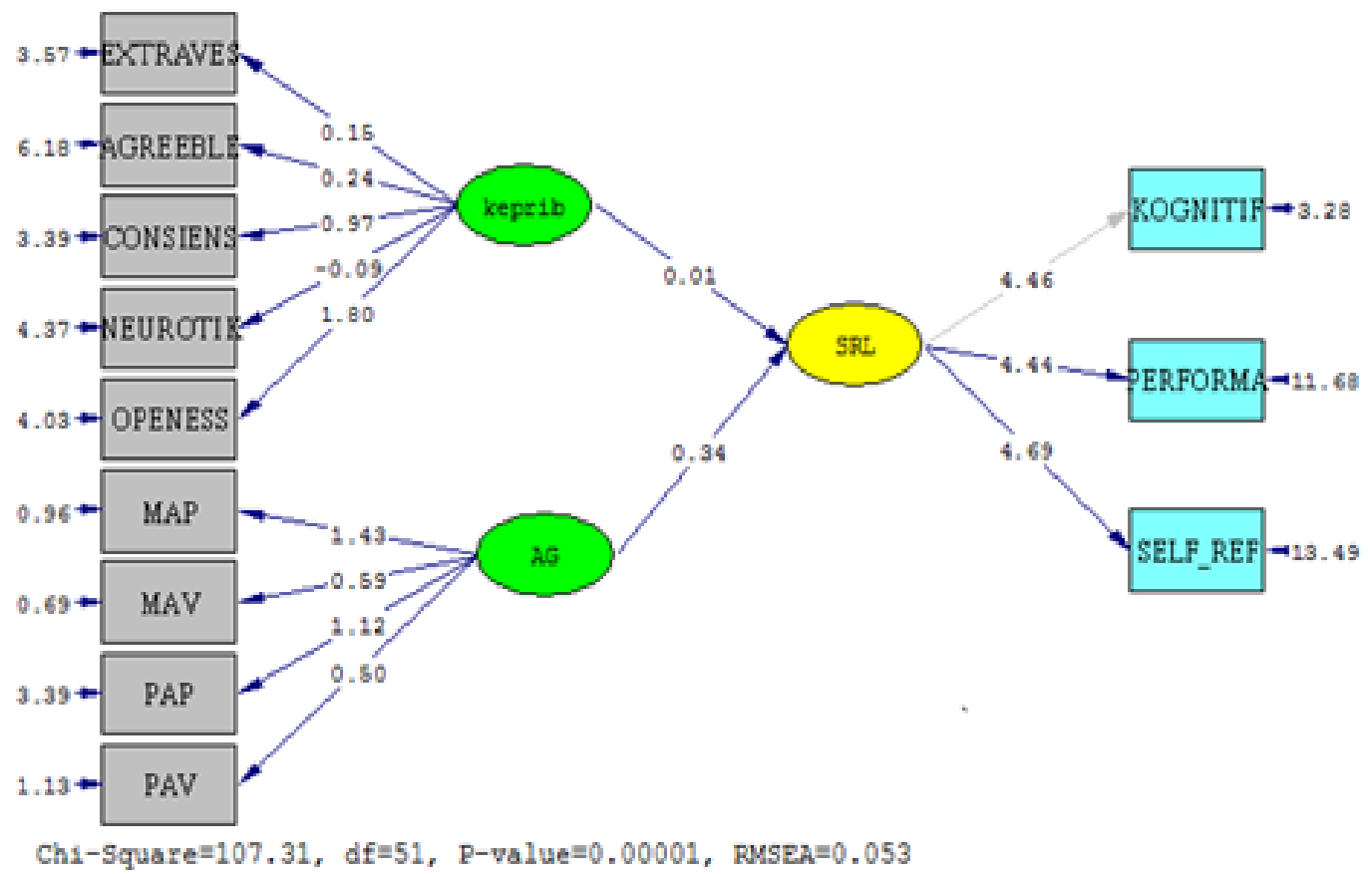

Gambar 2. Hasil analisis SEM 1

signifikan berpengaruh terhadap kepribadian, adalah kepribadian conscient dan openess.

Nilai t hitung yang signifikan pada taraf signifikansi $5 \%$ untuk variabel achievement goal terhadap SRL dan achievement goal terhadap kepribadian ataupun sebaliknya (3,48 > $1,98$ dan $8,63>1,98)$. Sementara itu, variabel kepribadian terhadap SRL tidak berpengaruh secara signifikan pada taraf signifikansi 5\% (Gambar 3)

Koefisien jalur dari kepribadian sebesar 0,01 (Gambar 4). Hal ini berarti kepribadian berpengaruh positif terhadap SRL. Koefisien achievement goal sebesar 0.34 terhadap SRL. Artinya terdapat pengaruh positif dari achievement goal terhadap SRL. Dengan kata lain, se- makin tinggi achievement goal seseorang, maka semakin tinggi pula SRL yang dimiliki. Selanjutnya, nilai koefisien kepribadian dan achievement goal sebesar 0,63 yang artinya kepribadian dan achievement goal saling berpengaruh positif. Didapatkan hasil (Tabel 2) bahwa model SEM tidak secara keseluruhan memiliki kemampuan yang baik dalam hal mencocokkan data sampel (good fit). Dengan kata lain, matriks kovarian estimasi model SEM terdapat perbedaan secara statistik terhadap matriks kovarian data sampel.

Berdasarkan hasil analisa data penelitian ini, diperoleh hasil bahwa Achievement Goal (AG) memiliki pengaruh yang signifikan terhadap SRL. Hal ini disebabkan karena SRL

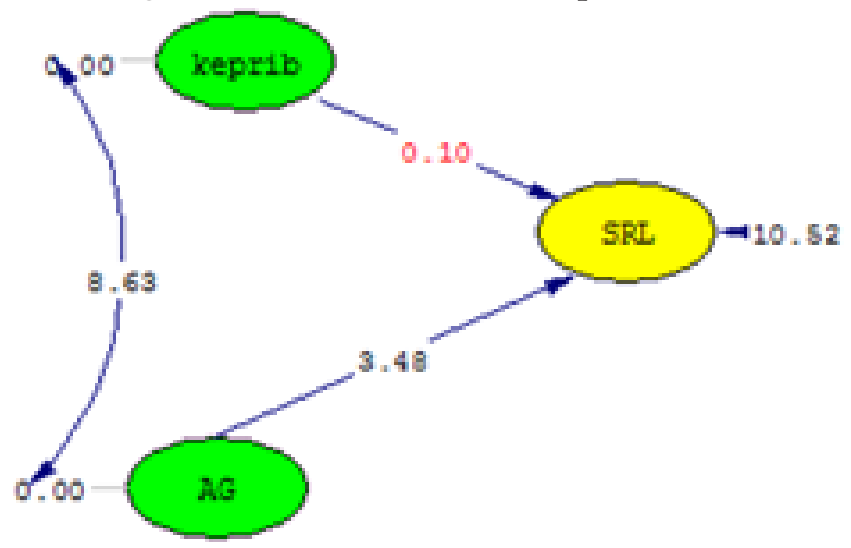

Gambar 3. Hasil T hitung variabel achievement goal terhadap SRL dan Achievement goal terhadap kepribadian

74 | Kemampuan Self-Regulated... 


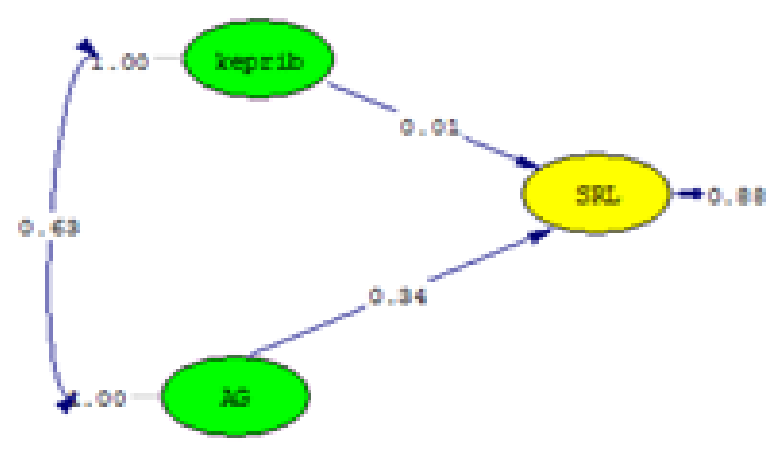

\section{Gambar 4. Hasil t hitung kepribadian terhadap SRL}

adalah mengatur atau merencanakan dengan sengaja apa yang dipikirkan, dirasakan, dan dilakukannya untuk mencapai tujuan (Boekaerts et al., 2000).

Berdasarkan definisi SRL ini dapat diketahui bahwa SRL dapat dilakukan ketika individu memiliki tujuan yang akan diraih khususnya dalam belajar. Hal ini jelas menunjukkan bahwa achievement goal merupakan bagian yang penting dalam SRL, sebab individu melakukan perencanaan dan pengelolaan terhadap aktivitas, pikiran, dan perasaannya jika ia memiliki tujuan.

Zimmerman (1989) menambahkan bahwa SRL adalah tindakan dan proses yang dilakukan individu (pembelajar) secara langsung guna mendapatkan informasi maupun keterampilan yang melibatkan agen, tujuan, dan alat bantu. Ia menyebutkan bahwa tujuan dalam belajar meliputi kelas, harga diri sosial, kesempatan bekerja setelah lulus, yang secara ekstensif dapat berbeda dan dalam waktu yang berbeda guna meraihnya. Sehingga jelas menurut definisi ini, bahwa SRL dilakukan ketika individu memiliki tujuan dalam belajar.

Menurut Zimmerman \& Martinez-Pons (1988) SRL dimunculkan individu secara metakognitif, motivasional, dan perilaku aktif dalam proses belajarnya. Secara lebih detail mereka menjelaskan dalam hal metakognisi, individu dengan SRL akan melakukan perencanaan, pengorganisasian, self instruksi dan self evaluasi pada setiap tahapan selama proses belajar. Pada motivasional, individu meyakini pada dirinya bahwa dirinya memiliki keyakinan diri/self-efficacy, kemandirian, dan memotivasi diri secara intrinsik. Selanjutnya dalam hal perilaku, individu memilih, menstruktur, dan menciptakan lingkungan fisik dan sosial guna mengoptimalkan usahanya. Penjelasan di atas menunjukkan bahwa individu dengan SRL secara sengaja dan aktif terlibat dalam proses belajarnya mulai dari

Tabel 2. Kecocokan Model Terhadap Data

\begin{tabular}{|c|c|c|}
\hline $\begin{array}{l}\text { Ukuran Uji Kecocokkan Model secara } \\
\text { Keseluruhan }\end{array}$ & $\begin{array}{l}\text { Nilai Patokan untuk } \\
\text { Kecocokkan Model }\end{array}$ & $\begin{array}{c}\text { Kecocokkan Model } \\
\text { terhadap Data }\end{array}$ \\
\hline Probabilitas dari $\mathrm{X}_{\text {hitung }}=0,00$ & $\geq 0,05$ & Tidak \\
\hline RMSEA $=0,053$ & $\leq 0,08$ & $\mathrm{Ya}$ \\
\hline $\mathrm{NFI}=0,92$ & $\geq 0,9$ & Ya \\
\hline $\mathrm{NNFI}=0,94$ & $\geq 0,9$ & Ya \\
\hline $\mathrm{CFI}=0,95$ & $\geq 0,90$ & Ya \\
\hline $\mathrm{IFI}=0,95$ & $\geq 0,9$ & Ya \\
\hline $\mathrm{RFI}=0,89$ & $\geq 0,9$ & Tidak \\
\hline $\mathrm{RMR}=0,32$ & $\leq 0,05$ & Tidak \\
\hline $\mathrm{SRMR}=0,052$ & $\leq 0,05$ & Ya \\
\hline $\mathrm{GFI}=0,96$ & $\geq 0,9$ & Ya \\
\hline $\mathrm{AGFI}=0,93$ & $0,8 \leq A G F I<0,9$ & Tidak (Marginal Fit) \\
\hline
\end{tabular}


merencakan, mengatur/mengelola, memberikan instruksi kepada diri sendiri hingga mengevaluasi diri dalam belajarnya.

Individu dengan SRL yang baik, akan memiliki achievement goal yang baik pula. Hal ini disebabkan karena individu dengan achievement goal akan memiliki alasan yang jelas yang akan dicapai dalam hal akademiknya. Menurut Pintrich (2000) achievement goal adalah alasan atau tujuan individu untuk mencapai sukses dalam tugasnya. Individu tersebut memiliki alasan untuk belajar dan mengerjakan tugas dengan jelas. Sehingga hal ini mengarahkan perilakunya untuk mengelola pikiran, perasaan, dan tindakannya untuk meraih tujuan tersebut.

Terdapat dua dimensi dalam achievement goal yakni mastery goal (mastery approach dan mastery avoidance) dan performance goal (performance approach dan performance avoidance). Mascret, Elliot, dan Cury (2015) menyatakan bahwa mastery goal adalah berusaha dengan keras untuk mengembangkan kompetensi melalui penguasaan dan mengembangan tugas, sedangkan performa goal adalah berusaha dengan keras untuk mempraktekkan, mendemonstrasikan kompetensi yang dimiliki kepada orang lain. Oleh karena itu, individu dengan achievement goal yang baik akan secara sadar dan aktif untuk mengelola dirinya baik pikiran, perasaan, dan perilakunya untuk mencapai tujuannya dalam belajar. Tidak mengherankan jika individu dengan achievemen goal yang baik akan memiliki SRL yang baik pula.

Individu dengan mastery goal yang baik akan berusaha untuk menguasai dan memahami tugas-tugas yang diberikan kepadanya dengan standar dari dalam dirinya untuk berkembang menjadi lebih baik dan memiliki pemahaman yang baik atau dalah istilah psikologi individu ini memiliki mastery approach. Sementara itu, individu dengan mastery avoidance, akan berusaha untuk menghindari agar tidak terlihat tidak paham atau tidak mengerti atau tidak belajar akan tugas-tugas yang dibebankan kepadanya serta menggunakan standar agar tidak terlihat tidak paham, dan tidak terlihat tidak benar dalam memahami tugas. Sehingga untuk menampilkan hal ini, individu akan melakukan usaha dengan meregulasi pikiraan, perasaan dan tindakannya dalam belajar (Pintrich, 2000).

Tindakan dalam meregulasi diri dalam belajar ini juga berlaku bagi individu dengan performance approach yang baik. Individu dengan performance approach yang baik akan terpusat agar tampak baik, menjadi yang terbaik dibandingkan dengan orang lain, menjadi yang terpintar dengan menggunakan standar normatif di kelas, membandingkan diri dengan orang lain (Pintrich, 2000), dengan demikian, individu itu akan berusaha dengan keras untuk melakukan SRL pada setiap tahapan SRL-nya.

Menurut Boekaerts et al. (2000) dalam proses SLR terdapat tiga tahap; pertama (tahap pemikiran awal), pada tahapan ini individu akan melakukan analisa terhadap tugasnya, dan memotivasi dirinya; tahap kedua (performance) individu akan mengontrol dirinya saat melaksanakan segala aktivitas untuk mencapai tujuan dan melakukan observasi diri melalui self recording dan self eksperimen; tahap ketiga adalah reflesksi diri individu melakukan penilaian terhadap performa yang sudah dilakukan dan melakukan reaksi diri baik secara emosi maupun kognisi atas performa yang telah dilakukan.

Pada individu dengan performance avoidance, akan cenderung menampilkan tugas-tugasnya dengan standar normatif agar tidak menjadi yang terburuk atau menjadi yang terendah di kelas. Individu ini akan lebih fokus untuk menghindari menjadi interior dan tidak terlihat bodoh dibandingkan orang lain (Pintrich, 2000). Individu ini akan melakukan tetap melakukan SRL meskipun dengan tingkat kesungguhan tidak sebaik dimensi achievement goal yang lain (mastery approach, mastery avoidance dan performance approach) sebab, indivdu ini menanamkan dalam dirinya, asalkan dirinya tidak menjadi yang terburuk. Hal ini sesuai dengan hasil penelitian peneliti sebelumnya, yang menyatakan bahwa performance avoidance memiliki hubungan terhadap personal growth initiative namun tidak signifikan dalam memengaruhinya (Saraswati, 2018).

Hasil lain yang didapat dari penelitian ini bahwa kepribadian tidak memiliki pengaruh yang signifikan terhadap SRL. Hal ini disebabkan 
karena pada uji statistik, kepribadian extraversi, agreeble, dan neurotiscm tidak memiliki pengaruh yang signifikan terhadap kepribadian itu sendiri. Pada kepribadian conscient dan openess-lah yang berpengaruh signifikan terhadap kepribadian. Kepribadian conscient adalah individu yang memiliki karakteristik yang terorganisasi, tertata, terhati-hati, dan memiliki disiplin diri yang tinggi, sedangkan kepribadian openess memiliki karakteristik imajinatif, bebas, menyukai variasi bukan sekedar rutinitas (Costa \& McCrae, 1985 dalam Hewstone, M. R. ,Fincham, F. D., $\&$ Foster, 2005).

Menurut Costa dan McCrae (dalam Pervin \& Daniel 2012), karakter kepribadian openness individu yang aktif mencari dan menghargai setiap pengalaman, mampu melakukan toleransi dan mengeksplorasi hal-hal yang tidak biasa. Individu yang memiliki dominasi yang tinggi pada openess memiliki rasa ingin tau yang tinggi, minat yang luas, kreatif, orisinal, imajinatif, dan tidak konservatif atau tradisional. Jelas bahwa individu dengan kepribadian openess memengaruhi kemampuan SRL-nya, sebab individu tersebut akan dengan terbuka, mudah dan mau mengekplorasi hal-hal baru jika dalam setiap tahapan SRL kurang sesuai dengan tujuan yang akan dicapainya. Individu tersebut akan lebih mudah dalam melakukan evaluasi jika dalam proses SRL-nya tidak berjalan sesuai harapan dan tidak mencapai target atau tujuan yang telah ditetapkan.

Hal yang sama juga akan berlaku pada kepribadian conscient. Individu dengan dominasi kepribadian conscient berpengaruh terhadap SRL sebab individu ini cenderung lebih tertata terorganisasi, berhati-hati, dan disiplin dalam menjalankan aktivitasnya. Sehingga individu ini akan lebih tertib dan disiplin dalam menjalannkan setiap proses SRL mulai dari tahapan pemikiran awal, performance hingga tahapan refleksi diri. Pendapat ini diperkuat dengan pendapat Costa dan McCrae (dalam Feist \& Feist, 2008), bahwa kepribadian conscientiousness memiliki tingkat organisasi, kekakuan, dan motivasi untuk berperilaku yang mengarah pada tujuan yang telah ditetapkannya. Selain itu, individu ini adalah individu dengan karakter pekerja keras, disiplin diri, tegas, gigih, rapi, tertata, ambisius, dan kaku.

\section{SIMPULAN}

Berdasarkan hasil penelitian, diketahui bahwa achievement goal memiliki pengaruh terhadap SRL. Artinya, semakin tinggi skor achievement goal individu maka semakin tinggi pula skor SRL yang dimiliki. Selain itu, kepribadian secara keseluruhan tidak memiliki pengaruh yang signifikan terhadap SRL, meskipun demikian, kepribadian openess dan conscient memiliki pengaurh terhadap SRL, artinya semakin tinggi atau dominan kepribadian tersebut maka semakin tinggi pula kemampuan SRL yang dimiliki individu. Terakhir, kepribadian dan achievement goal saling memengaruhi.

Penelitian ini memiliki implikasi bagi peneliti selanjutnya untuk lebih mengembangkan penelitian di bidang psikologi pendidikan khususnya terkait self regulated learning dan alat ukurnya. Peneliti selanjutnya, dapat meneliti lebih dalam pengaruh kepribadian conscient dan openess, agar lebih memahami seberapa besar pengaruh kepribadian tersebut terhadap SRL, penambahan variabel lain serupa dengan pola asuh dan budaya untuk mengetahui apakah benar memang hanya dua kepribadian tersebut yang berpengaruh terhadap SRL. Peneliti selanjutnya, dapat memperluas subjek penelitian dengan latar belakang status sosial, pendidikan, agama, dan lainnya, untuk memperkaya penelitian tentang SR, serta dapat memperluas lingkup penelitian

\section{REFERENSI}

Boekaerts, M., Pintrich, P. R., \& Zeidner, M. (2000). Handbook of self regulation. New York: Academic Press.

Broadbent, J., \& Poon, W. L. (2015). Self-regulated learning strategies \& academic achievement in 
online higher education learning environments: A systematic review. Internet and Higher Education, 27, 1-13. https://doi.org/10.1016/j.iheduc.2015.04.007

Feist, J., \& Fesit, G.J. (2008). Theories of personality. Yogyakarta: Pustaka Pelajar.

Hewstone, M. R. ,Fincham, F. D., \& Foster, J. (2005). Adolescence and adulthood. Psychology. Oxford: Blackwells/ British Psychological Society.

John, O. P., Robins, R. W., \& Pervin, L. A. (2008). Handbook of personality third edition theory and research. New York: The Guilford Press.

Mascret, N., Elliot, A. J., \& Cury, F. (2015). Extending the $3 \times 2$ achievement goal model to the sport domain: The $3 \times 2$ Achievement Goal Questionnaire for Sport. Psychology of Sport and Exercise, 17, 7-14. https://doi.org/10.1016/j.psychsport.2014.11.001

Peraturan Menteri Pendidikan Dan Kebudayaan Republik Indonesia. Tentang Hari Sekolah Nomor 23 Tahun 2017. Direktur Jenderal Peraturan Perundang-Undangan Kementerian Hukum Dan Hak Asasi Manusia Republik Indonesia: Jakarta.

Pintrich, P. R. (2000). An Achievement Goal Theory Perspective on Issues in Motivation Terminology, Theory, and Research. Contemporary Educational Psychology, 25(1), 92-104. https://doi.org/10.1006/ceps.1999.1017

Pintrich, P. R. (2000). Handbook of Self Regulation. United Kingdom: Academic Press.

Rizky, A. A. (2015). Problematika pembelajaran system full day school siswa kelas 1 sdit al-irsyad Tegal. Unpublished minor thesis. Universitas Islam Negeri Walisongo Semarang.

Santrock, J. W. (2003). Adolescence perkembangan remaja edisi keenam. Jakarta: Erlangga.

Saraswati, P. (2018). Goal Achievement as a Predictor of Personal Growth Initiative for Generation Z. Proceedings of the 4th ASEAN Conference on Psychology, Counselling, and Humanities (ACPCH 2018). https://doi.org/10.2991/acpch-18.2019.80

Schultz, D. ., \& Schultz, S. E. (2006). Psychology and work today. London: Pearson Prentice Hall.

Schunk. H.D., Pintrich, P. R., \& M. L. J. (2008). Motivational in education: theory, research, and application. Ohio: Pearson Press.

Winarni, B. (2015). Pengaruh penerapan full day school terhadap Kedisiplinan Siswa Mi Muhammadiyah PK Kartasura Tahun Ajaran 2014/2015. Unpublished minor thesis. Universitas Muhammadiyah Surakarta.

Zimmerman, B.J., Bonner, S. \& Kovach, R. (1996). Developing self-regulated learners beyond achievement to self efficacy. Washington: American Psychological Assosiation.

Zimmerman, B. J. (1989). A Social Cognitive View of Self-Regulated Academic Learning By: Barry J . Zimmerman A Definition of Self-Regulated Learning EBSCOhost Page 2 of 23 A View of Student Self-Regulated Academic Learning Social Cognitive Assumptions. Journal of Education Psychology, 81(3), 1-23.

Zimmerman, B. J., \& Martinez-Pons, M. (1988). Construct validation of a strategy model of student self-regulated learning. Journal of Educational Psychology, 80(3), 284-290. https:// doi.org/10.1037/0022-0663.80.3.284 